\title{
Novel Over-Expanded Six-Stroke Engine Mechanism
}

\author{
Emre ARABACI*, Bayram KILIÇ \\ Mehmet Akif Ersoy University, Department of Motor Vehicles and Transportation Technologies, Burdur
}

\begin{abstract}
Some of the exhaust waste heat of the four-stroke engines can be transformed into useful work in a variety of ways. With the exhaust heat recovery from the six-stroke engine mechanisms, the goal is to increase the thermal efficiency by converting the waste heat of useful work for the engine. Despite the availability of many patents related to six-stroke engines today more study and research are required to be used industrially. In this study, instead of a conventional six-stroke engine, a variable-stroke six-stroke engine mechanism was theoretically examined. An idealized thermodynamic model of the novel mechanism was constructed, kinetic and dynamic analyzes were made, and the design parameters were examined in comparison with the conventional engine mechanism. As a result, compared to the conventional six-stroke engine mechanism under the same conditions as this study, while the engine moment was increased by $10 \%$, whereas the load on the crankshaft increased by only $1 \%$.
\end{abstract}

Keywords: Six stroke, Over-expansion, Variable stroke, Planetary gear mechanism, Dynamic analysis.

\section{Yeni Aşırı Genişleşmeli Altı Zamanlı Motor Mekanizması}

\begin{abstract}
$\ddot{O} \mathbf{z}$
Dört zamanlı motorların egzoz atık ısısının bir kısmı, çeşitli şekillerde faydalı işlere dönüştürülebilir. Altı zamanlı motor mekanizmalarını egzoz ısısı geri kazanımı ile amaç, motor için faydalı işlerin atık 1sısını dönüştürerek ısıl verimliliği arttırmaktır. Bugün altı zamanlı motorlarla ilgili birçok patentin varlığına rağmen, endüstride daha fazla çalışma ve araştırma yapılması gerekmektedir. Bu çalışmada, geleneksel altı zamanlı bir motor yerine, değişken stroklu altı zamanlı bir motor mekanizması teorik olarak incelenmiștir. Yeni mekanizmanın idealize edilmiş bir termodinamik modeli oluşturuldu, kinetik ve dinamik analizler yapıldı ve tasarım parametreleri geleneksel motor mekanizmasına göre incelendi. Sonuç olarak, bu çalışma ile aynı koşullar altında geleneksel altı zamanlı motor mekanizmasına kıyasla, motor momenti \%10 artarken, krank milindeki yük yalnızca $\% 1$ artmıştır.
\end{abstract}

Anahtar Kelimeler: Altı-zamanlı, Aşırı genleşmeli, Değişken kurs, Planet dişli mekanizması, Dinamik analiz.

\section{Introduction}

Today, internal combustion engines are used in many industries. Internal combustion engines are seen as a source of many problems in addition to the many advantages they provide. With the increase in population and the development of technology, it also increases the demand for internal combustion engines. However, these engines, which are dependent on fossil resources, cause air pollution due to the exhaust emissions they emit, as well as causing the energy sources to be consumed rapidly [1].

In recent years research interest in internal combustion engines has been on small volume, high performance and low fuel consumption [2-5]. Commonly used internal combustion engine cycles are four-stroke. In Miller or Atkinson cycle engines commonly used in hybrid vehicles, the expansion stroke is longer than the compression stroke [5, 6]. However, throughout the history of technology, many engine cycles were created as alternatives to four-stroke engine cycle. The six-stroke cycle is among the most important of these alternative engine cycles [7].

*Sorumlu yazar: earabaci@mehmetakif.edu.tr

Geliş Tarihi:29.05.2018, Kabul Tarihi: 08.11.2018 
The six-stroke cycle is simply based on the principle of adding a steam cycle in addition to a four-stroke cycle and combining these two different cycles and using the waste heat of the exhaust gas in the steam cycle [7-9]. There are also six-stroke engine designs based on different strategies. Along with the development of the technology, this strategies have undergone various changes and many sixstroke engine designs have emerged [6].

The study on six-stroke engines dates back to the end of the 19th century. The first study to describe the related principles of the six-stroke engines was made by Dyer in 1920. A lot of study has been done about the six-stroke engines and a large part of which have been patented. [7-9].

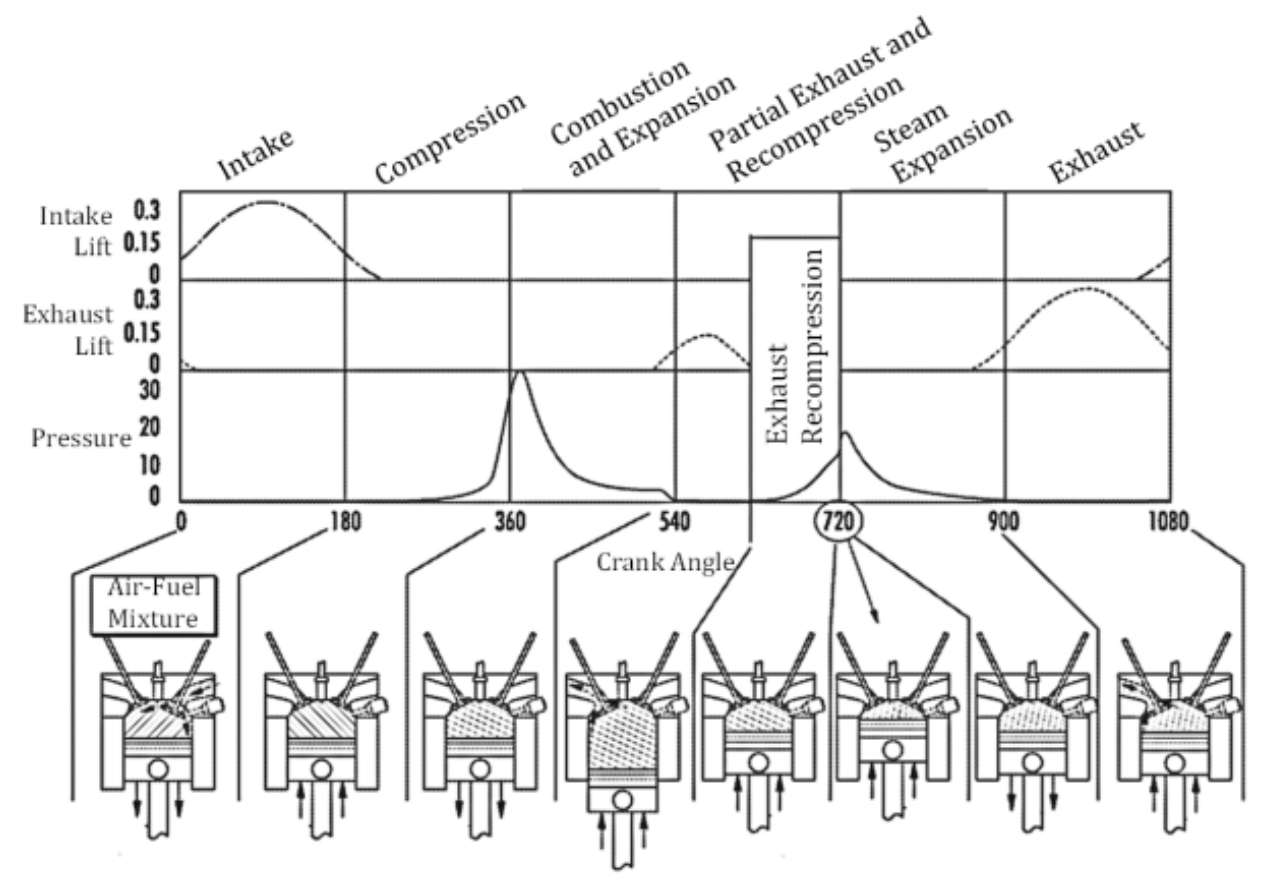

Figure 1. Operation of the six-stroke engine with exhaust heat recovery [10]

Figure 1 shows the operation of a six-stroke engine in which exhaust heat recovery is performed with water injection support. With water injection, some of the exhaust waste heat can be converted into work. The basic parameters are the partial exhaust rate, the water temperature, the amount of water and timing of injection. The partial exhaust ratio can be replaced by the exhaust cam profile [10]. Another parameter that affects the exhaust heat recovery is the Liedenfrost effect. When the Liedenfrost effect is occured, the desired exhaust heat recovery is not possible since post-evaporation of the injected water will be delayed [11]. For this reason it is imperative that the water injection parameters are adjusted and optimized so as not to have a Liedenfrost effect [12].

There are also six-stroke engine designs where water injection is not used. The purpose of these engines is to reduce the internal temperature of the engine by the free stroke slightly before the suction stroke and to increase the volumetric efficiency [13].

Especially for passenger vehicles, the automotive manufacturers' reluctance to produce diesel engines, the trend towards hybrid engine vehicles, and the development of internal combustion engines with alternative mechanisms is also accelerating [14]. In hybrid vehicles, instead of conventional engines, higher thermal efficiency Miller or Atkinson cycle engines are preferred [15]. The patent on "over expanded engine" was first registered on 1882 [6]. By developing this design, It became the basis of today's Atkinson engines using a single piston instead of a reciprocating piston. The main purpose of the Atkinson cycle are to increase the thermal efficiency [16]. Although the Atkinson cycle is structurally based on the Otto cycle, the complex joints between the crankshaft and the piston is the biggest difference that separates the two designs. Today, these complex joints are being tried to be reduced with gear systems [17]. The Miller cycle is the modernized version of the Atkinson cycle. Designed to operate in an engine Atkinson cycle, it is possible to achieve the same desired results of a unique valve timing when designed to operate on a similar engine Miller cycle while complex mechanical linkages are needed [18]. 
There are also engine mechanisms where the planetary gear mechanism is used. Nowadays, in engine design studies, alternative engine designs are tried to be created by taking advantage of the advantages of planetary gear mechanism [19]. Similar to the new mechanism described on this paper, the compact and modular Atkinson engine, the CTL engine (An atkinson cycle engine designed by the CTL Engineering Company), is a system of fixed outer gear and gear moving within outer gear. The CTL engine is very different from the Atkinson engine in terms of linkage type. The inner gear is also crankshaft bearing [20].

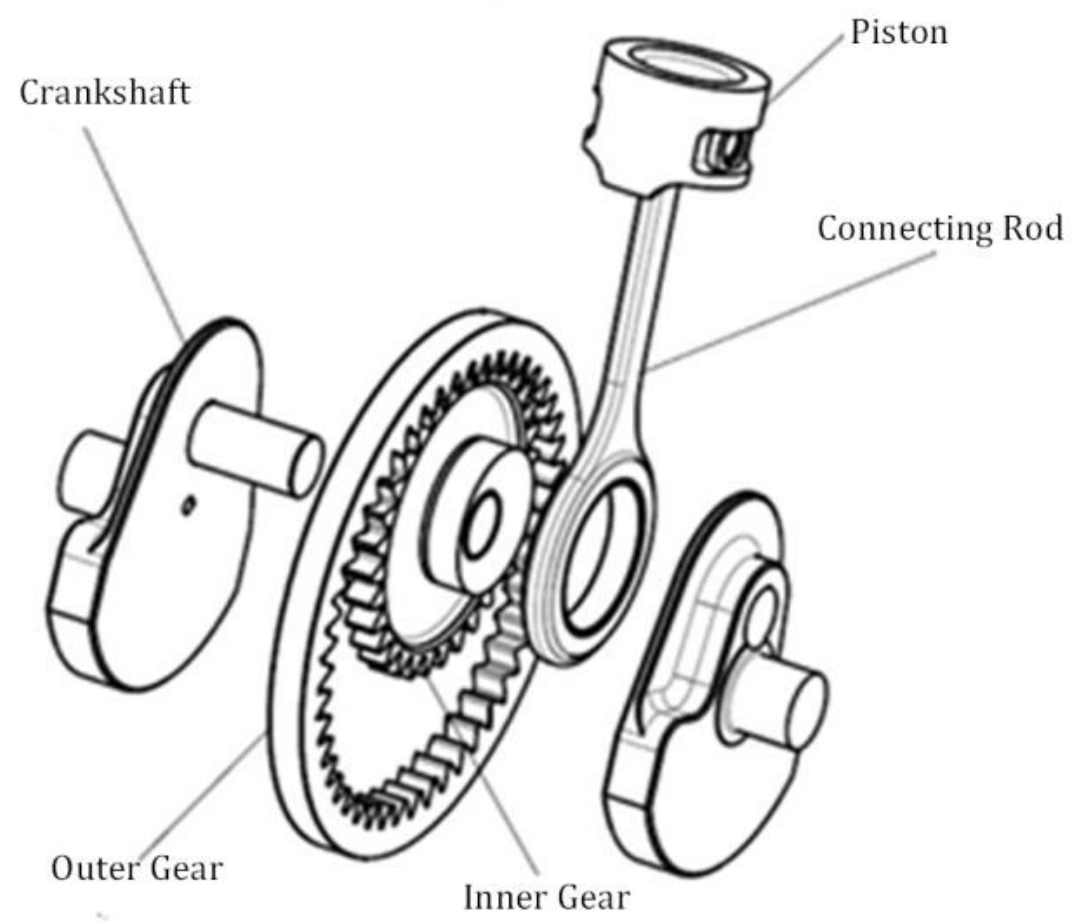

Figure 2. The parts of CTL engine [21]

Other engine designs are similar to the piston movement towards the CTL engine mechanism, while Lugo [22] and Umotor [23] are examples. In this engine mechanism, the outer gear is fixed on the engine body to guide the inner gear outer gear while moving with the crankshaft. It is a design similar to the CTL Engine in UMotor.

A simple planetary gear system is also used in the Waissi engine [24], which has a boxer engine design. In this design, the two pistons are directly connected (integrated) and there is no connecting rod as in conventional systems. The basic mechanism in all these engines is Hypocycloid or hypotrochoid gear mechanism [25]. By providing this motion in the engine mechanism, different movements are obtained than the piston movement obtained by the conventional crank-conrod mechanism [26].

When the literature is examined, various mechanisms and strategies have been developed after the invention of the over-expanded enginer. However, although there are many studies on six-stroke engines, there is no over-expanded six-stroke engine mechanism. The mechanisms in the literature are very difficult to use in six-stroke engines. All of the over-expanded engine mechanisms are designed for conventional four-stroke engines. Since the cycle processes in six-stroke engines is quite different from that of conventional four-stroke engines, a special design has to be made in order to create over expansion in six-stroke engines. In this study, a simplified design model for the novel six-stroke cycle engine, which is not included in the literature for the time being, has been established. Mechanic behaviors are investigated on the generated model.

\section{Analysis of the Mechanisim}

In this study, the kinetic analysis of the novel mechanism was performed. With this kinematic analysis, the motion equations of the mechanism were obtained. Dynamic analysis was then performed to 
determine the force resultants at the linkage points. In order to determine the effects of the mechanism on the engine performance, a simplified model was formed and thermodynamic analysis was performed.

\subsection{Kinematic analysis}

The novel mechanism is as shown in Figure 3. In the novel mechanism, there is an inner gear that moves in a fixed outer gear to the engine block. The crankshaft connecting rod bearing is positioned at the center of the inner gear. The connecting rod is positioned on the origin (far from the origin or axial misalignment) of the internal gear. In the initial position, the piston is in the top dead center (TDC), while the axial misalignment (or eccentricity) is in the positive $y$-axis direction.

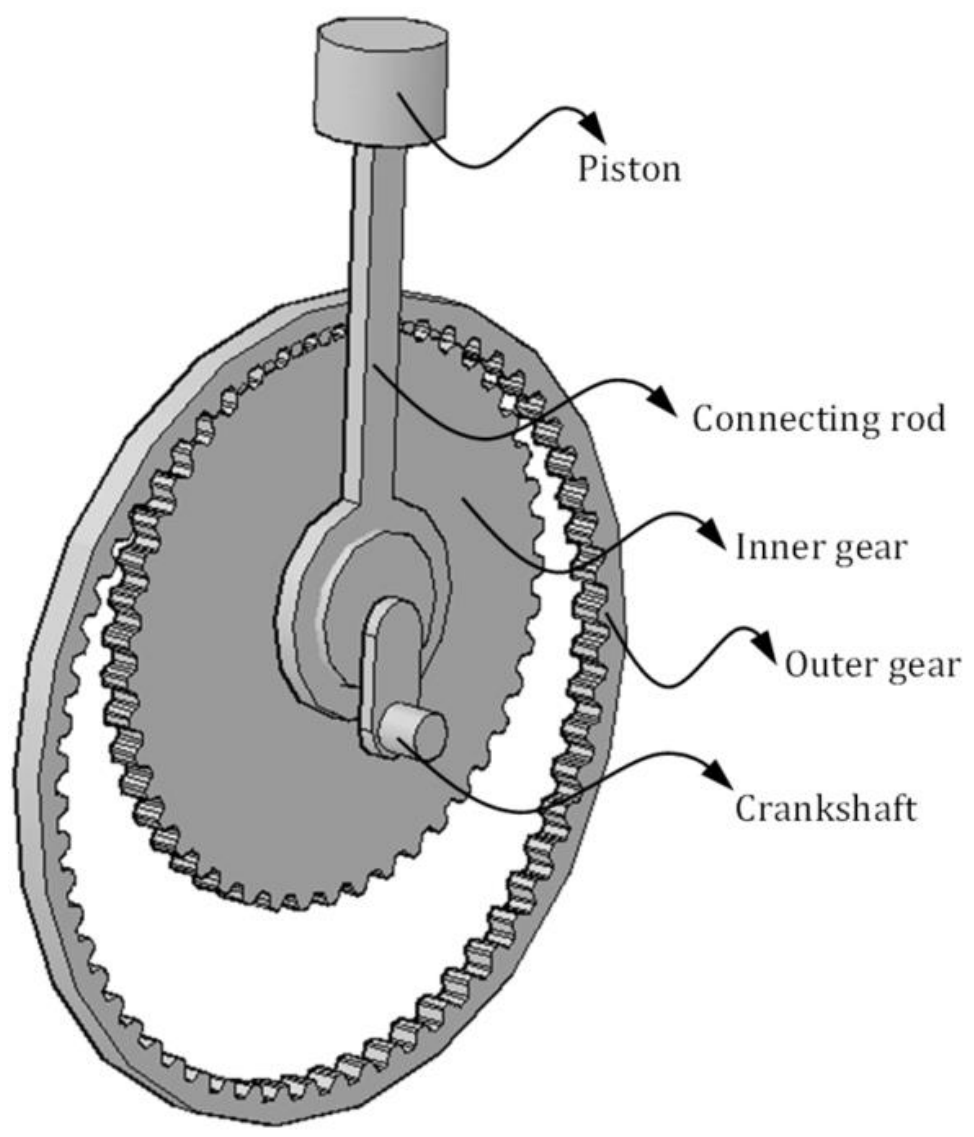

Figure 3. Novel engine desing mechanism

The main purpose of this mechanism is similar to the Atkinson engines, in that the expansion process, which is longer than the compression process, is mechanically created by means of the gears. Atkinson engines are basically four-stroke engines and the cycle is completed in two full crankshaft revolutions. Since the cycle is completed in three full crankshaft rotations of six-stroke engines, the ratio of the inner gear to the external gear is set at $3 / 4$ to achieve different cycle paths. This rate changes the behavioral characteristics of the mechanisms described in ref. [20] and ref [25].

The mechanism presented on this paper is based on the CTL engine mechanism [20]. The CTL engine mechanism was modified to create an over-expanded six-stroke cycle engine mechanism.

The schematic representation of Figure 3 is as in Figure 4. The point $A$, which is the center of the crankshaft, is regarded as the origin. The distance between points $A$ and $B$, the radius $(r)$, the distance between points $B$ and $C$, the axial offset of the $\operatorname{rod}(d)$, and the distance between points $C$ and $D$ are the connecting length $(l)$. Piston offset is expressed by $(e)$. For such a system, the outer gear diameter is $8 r$ and the inner gear diameter is $6 r$. 


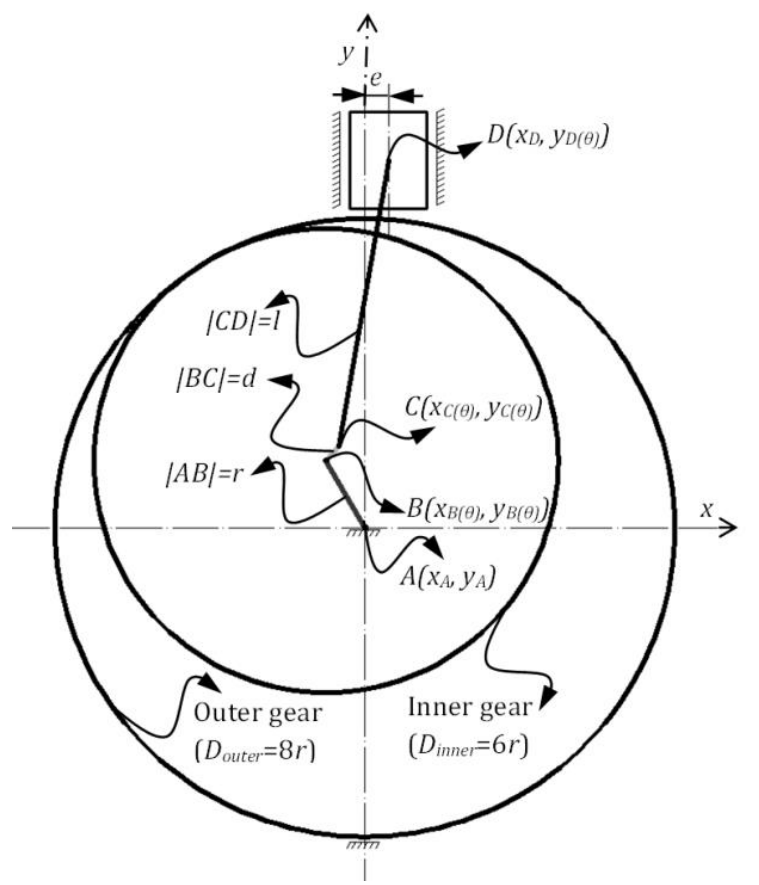

Figure 4. Schematic representation of the novel design

The points and angles used in the model are shown in Figure 5. When the crankshaft moves counter clockwise (CCW) as far as the angle $\theta$, the connecting axis moves clockwise $(\mathrm{CW})$ to the angle $\alpha$. In this case, the relation between $\theta$ and $\alpha$ angle can be expressed as follows. Here $r_{i o}$ is the ratio of the diameter of the inner and outer gear and this ratio is constant for this study [20,25]

$$
\begin{aligned}
& \alpha=\frac{\theta}{r_{\text {io }}} \\
& r_{\text {io }}=\frac{n_{\text {inner }}}{n_{\text {outer }}}=\frac{D_{\text {inner }}}{D_{\text {outer }}}=\frac{3}{4}
\end{aligned}
$$

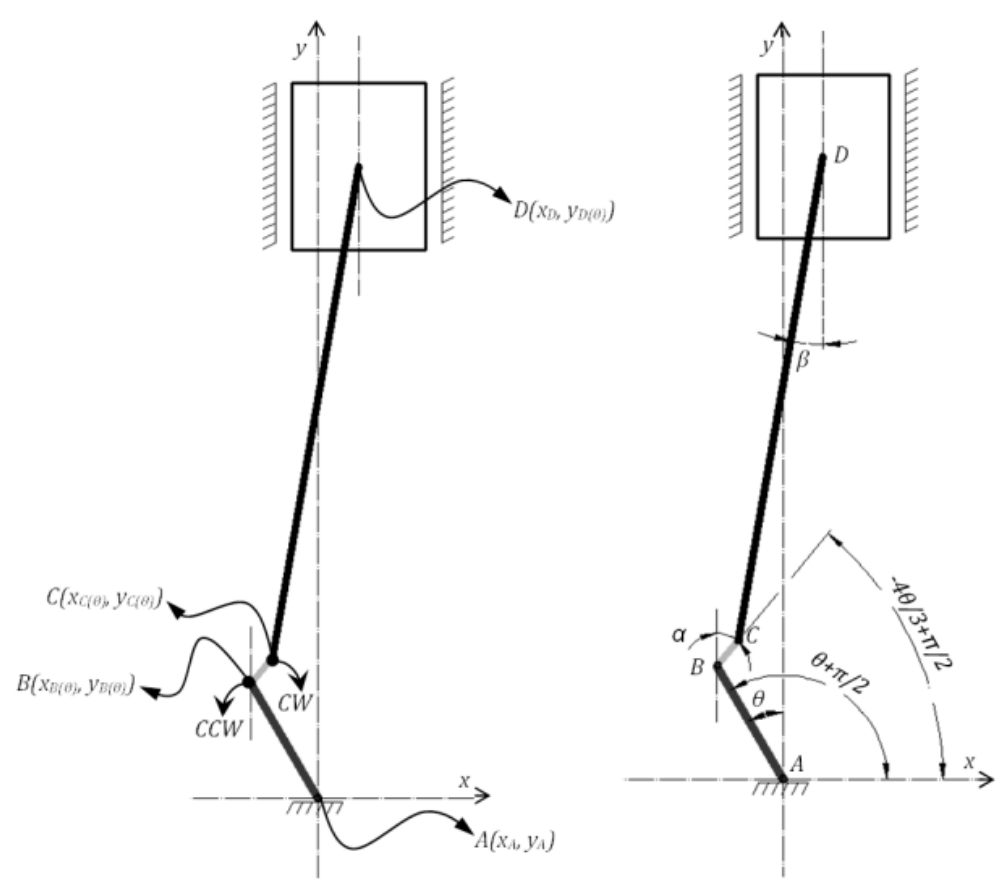

Figure 5. Notations used in calculations 
Initially, since the axial offset of the conrod is at the $y$-axis, the $\gamma$-angle is $\pi / 2 \mathrm{rad}$. However, when it is assumed that an is the origin, $x_{A}=0$ and $y_{A}=0$. The variation on the coordinates of the joint points $B$ and $C$ with respect to the angle $\theta$ is expressed as follows.

$$
\begin{aligned}
& x_{B(\theta)}=r \cdot \cos \left(\theta+\frac{\pi}{2}\right) \\
& y_{B(\theta)}=r \cdot \sin \left(\theta+\frac{\pi}{2}\right) \\
& x_{C(\theta)}=d \cdot \cos \left(-\frac{4 \theta}{3}+\frac{\pi}{2}\right)+r \cdot \cos \left(\theta+\frac{\pi}{2}\right) \\
& y_{C(\theta)}=d \cdot \sin \left(-\frac{4 \theta}{3}+\frac{\pi}{2}\right)+d \cdot \sin \left(\theta+\frac{\pi}{2}\right)
\end{aligned}
$$

In conventional mechanics, points $B$ and $C$ are actually the same points, and in the conventional system the path of movement of the point $C$ is circular. In the new mechanism, as the coordinates of points $B$ and $C$ change depending on the angle $\theta$, the path of motion of point $C$ is circular, and the path of movement of point $C$ varies on each crankshaft rotation, as shown in Figure 6.

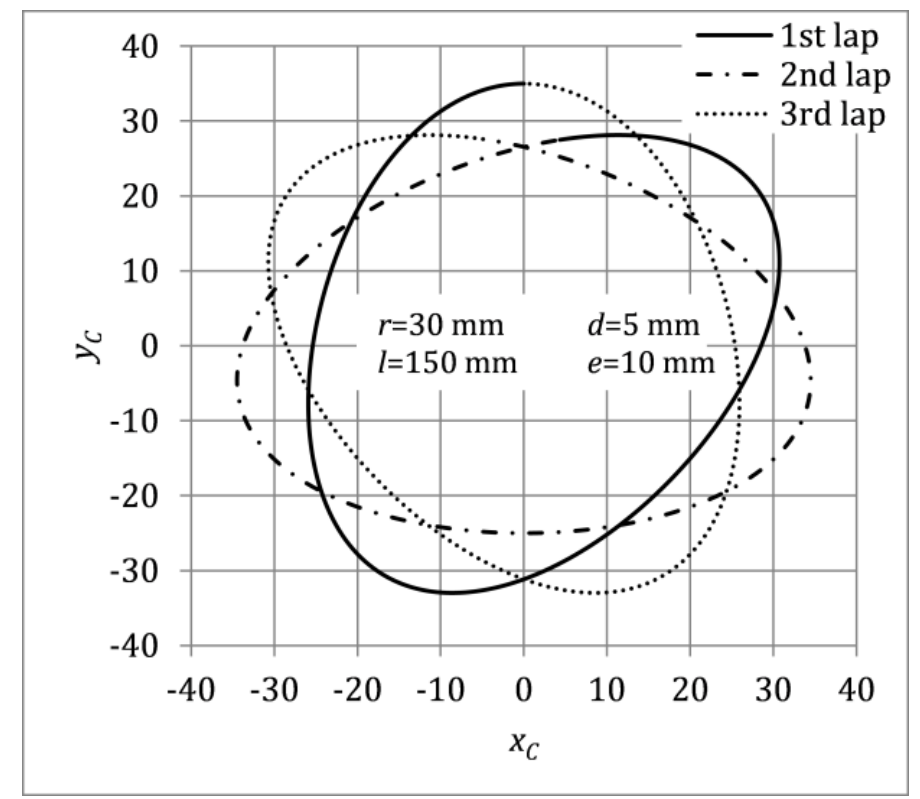

Figure 6. Movement path of the point $\mathrm{C}$ in the novel design

The point $D$ is the piston pin linkage, and the change of the point $D$ coordinates with respect to the angle $\theta$ is expressed as follows.

$$
\begin{aligned}
& x_{D}=e \\
& \begin{aligned}
y_{D(\theta)}=\left(l^{2}-(\right. & \left.\left.l-d\left(\cos \left(-\frac{4 \theta}{3}+\frac{\pi}{2}\right)\right)+r\left(\cos \left(\theta+\frac{\pi}{2}\right)\right)\right)^{2}\right)^{0.5}+d\left(\sin \left(-\frac{4 \theta}{3}+\frac{\pi}{2}\right)\right) \\
& +\left(\sin \left(\theta+\frac{\pi}{2}\right)\right)
\end{aligned}
\end{aligned}
$$



as follows.

Accordingly, $s_{(\theta)}$, which is the distance from the TDC with respect to the angle $\theta$, is expressed

$$
s_{(\theta)}=s_{\max }-y_{D(\theta)}
$$

Depending on the angle of $\theta$ and angular velocity of $\omega$, the instantaneous velocity and acceleration values can be calculated as follows.

$$
\begin{aligned}
& v_{(\theta, \omega)}=\omega \frac{d s}{d \theta} \\
& a_{(\theta, \omega)}=\omega^{2} \frac{d s^{2}}{d^{2} \theta}
\end{aligned}
$$

\subsection{Dynamic analysis}

In reciprocating internal combustion engines, the main force is the gas force which is generated by the effect of the gas pressure generated by the combustion effect on the piston surface. All components in the force analysis have been accepted as rigid and massless, since this paper will deal with the novel system with a conventional system. Force analysis is performed on a model without inertia forces, since the joint elements are considered to be rigid and massless. The gas force coming from the effect of gas pressure can be expressed as follows.

$$
F_{g(\theta)}=A_{p i s}\left(P_{g(\theta)}-P_{a t m}\right)
$$

When force analysis is performed, a free-body diagram is created on the simplified mechanism. The free body diagrams for the novel mechanism are as shown in Figure7.

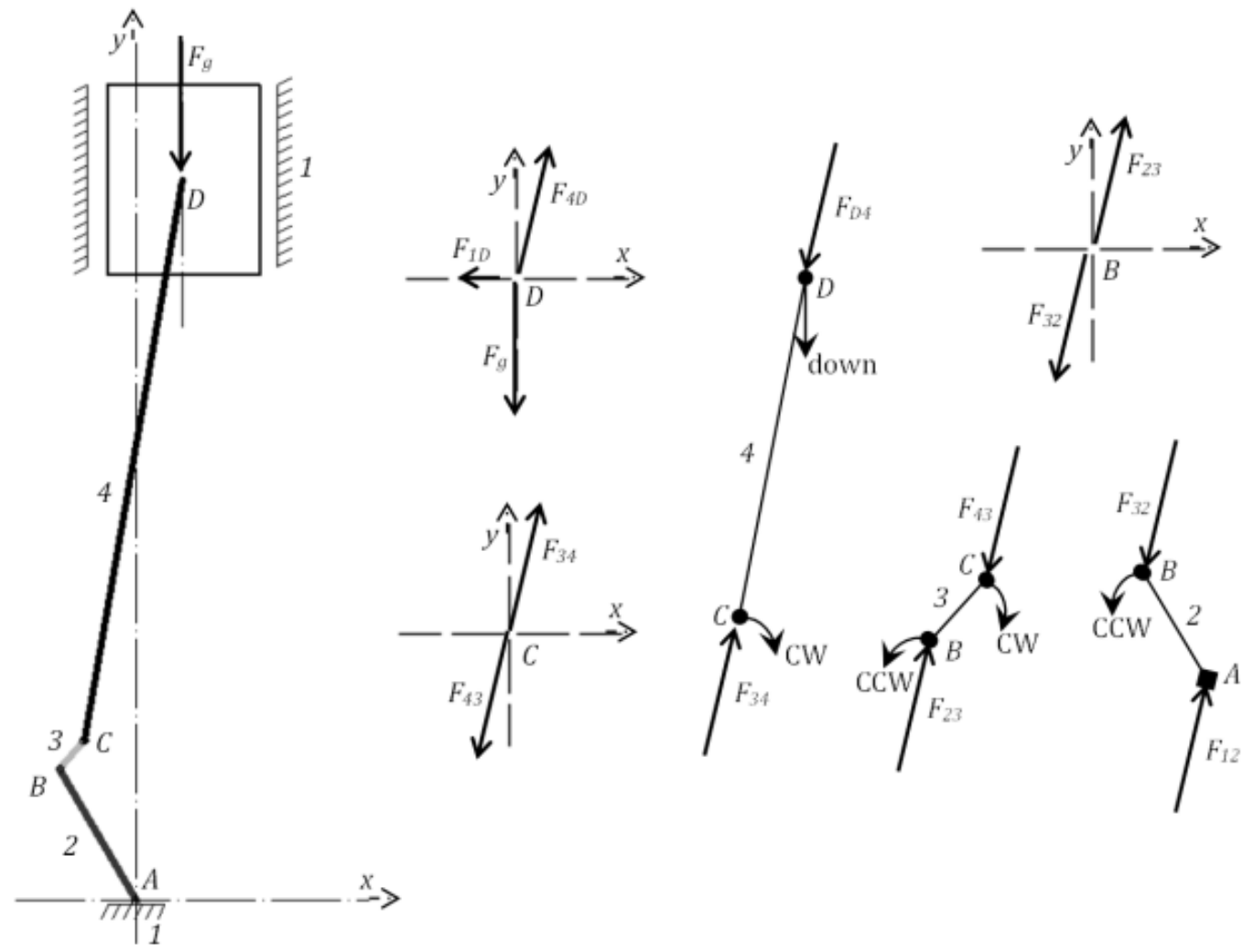

Figure 7. The free body diagrams for the novel mechanism 
The forces on point $D$ are $F_{g}, F_{4 d}$ (acting on the connecting rod) and $F_{1 d}$ (acting on the cylinder wall) forces, respectively. The relationship between these forces is as follows.

$$
\begin{aligned}
& F_{g}=-F_{4 D y}=-F_{4 D} \cos \beta \\
& F_{1 D}=-F_{4 D x}=-F_{4 D} \sin \beta \\
& \sin \beta=\frac{x_{D}-x_{C(\theta)}}{c} \\
& \cos \beta=\frac{y_{D(\theta)}-y_{C(\theta)}}{c}
\end{aligned}
$$

The force acting on point $B$ is the $F_{32}$, which is the force that rotates the crankshaft. Here $F_{32}$ is a resultant force and the force that acts on the joint bearing and the force that rotates the crankshaft. The components of the force $F_{32}$ are as follows. Here, a coordinate plane rotated in the direction of the $\theta$ angle, as shown in Figure 8, was created at point $B$, perpendicular to and parallel to the $A B$ joint.

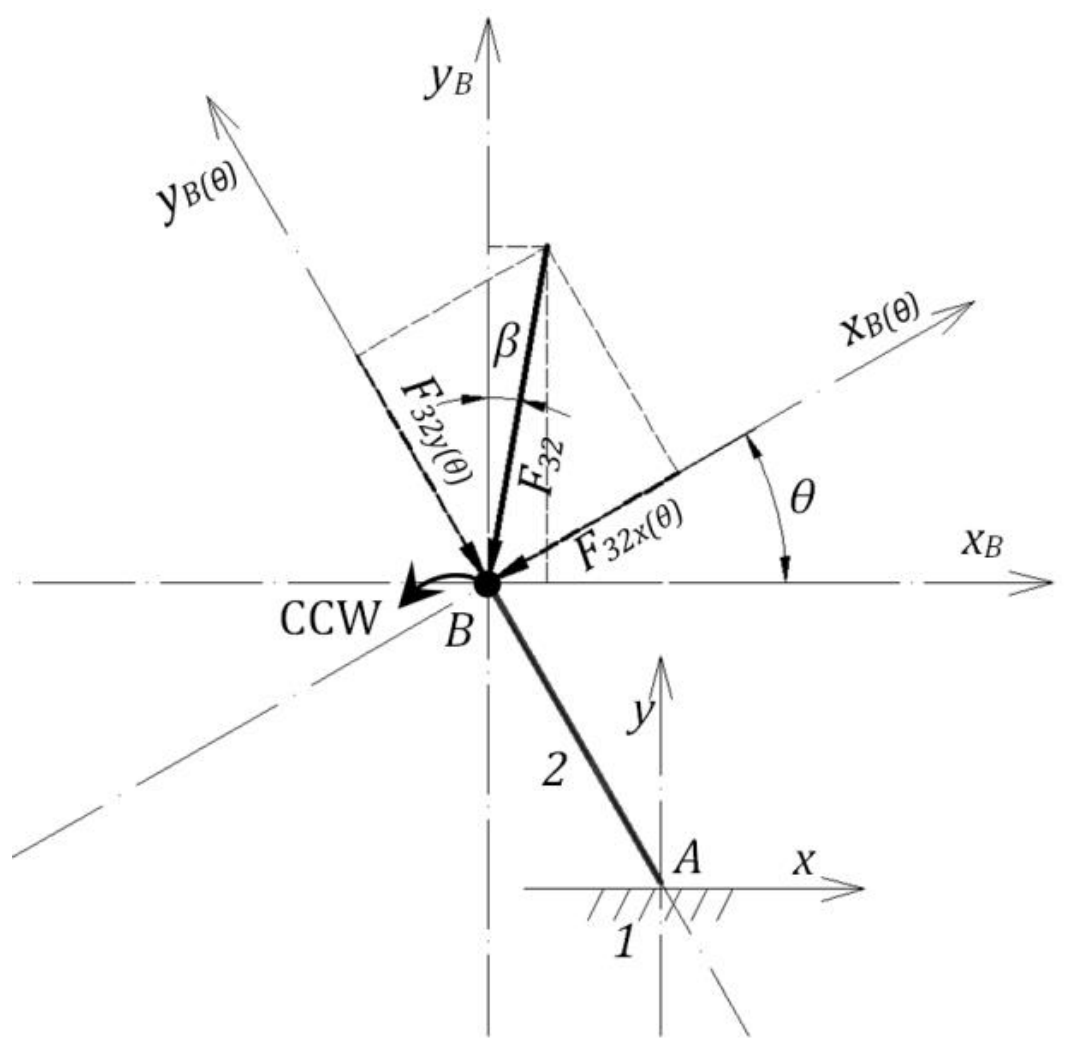

Figure 8. Rotated coordinate plate

According to Figure 8, the force that forms the moment on the crankshaft and perpendicular to point $B$ is expressed as follows.

$$
F_{32 x(\theta)}=F_{32} \sin (\beta+\theta)=F_{g}\left(\frac{x_{D}-x_{C(\theta)}}{y_{D(\theta)}-y_{C(\theta)}} \cos \theta+\sin \theta\right)
$$

The force acting on the crankshaft bearing in the same way is expressed as follows.

$$
F_{32 y(\theta)}=F_{32} \cos (\beta+\theta)=F_{g}\left(\cos \theta-\frac{x_{D}-x_{C(\theta)}}{y_{D(\theta)}-y_{C(\theta)}} \sin \theta\right)
$$


The moment generated on the crankshaft can be expressed as follows.

$$
\tau_{(\theta)}=F_{32 x(\theta)} r=F_{g}\left(\frac{x_{D}-x_{C(\theta)}}{y_{D(\theta)}-y_{C(\theta)}} \cos \theta+\sin \theta\right) r
$$

$\boldsymbol{P}_{\boldsymbol{g}}$ and $\boldsymbol{F}_{\boldsymbol{g}}$ are constantly changing depending on $\boldsymbol{\theta}$ and it is wrong to accept these values as constant. For this reason, a simple thermodynamic model have to be developed to analyze the whole cycle in order to calculate $\boldsymbol{P}_{\boldsymbol{g}}$ and $\boldsymbol{F}_{\boldsymbol{g}}$.

\subsection{Thermodynamic model for six-stroke cycle}

In six-stroke engine cycles, two power strokes occur in one cycle. The first power stroke is the result of the combustion of the fuel and the second power stroke is the steam power obtained by injecting a noncombustible liquid (water) into the hot waste exhaust gases [9]. For the over-expanded six-stroke cycle model, an idealized cycle model was established according to refs. 8, 10, 27 and 28. Processes of the novel mechanism cycle are presented according to Table 1.

Table 1. Processes of the novel cycle [28, 29]

\begin{tabular}{|c|c|c|c|}
\hline Range & Process & Condition & $\begin{array}{l}\text { Equations for temperature and } \\
\text { pressure }\end{array}$ \\
\hline $0-1$ & Suction & Isobaric & $T_{1}=\frac{n_{\text {mix }} T_{0}+n_{\text {res }} T_{\text {res }}}{n_{\text {mix }}+n_{\text {res }}} \quad P_{1}=P_{0}$ \\
\hline $1-2$ & Compression & Polytrophic & $T_{2}=T_{1} \varepsilon^{k_{p 1}-1}$ \\
\hline $2-3$ & Adiabatic Combustion & Isochoric & $T_{3}=T_{\text {adiabatic }} \quad P_{3}=\frac{n_{3} T_{3} P_{2}}{n_{2} T_{2}}$ \\
\hline $3-4$ & Expansion & Polytrophic & $T_{4}=\frac{T_{3}}{\varepsilon^{k p_{2}-1}}$ \\
\hline $4-5$ & Pressure Blowdown & Isochoric & $P_{5}=P_{0}$ \\
\hline $5-6$ & Partial exhaust & Isobaric & $n_{6}<n_{5}$ \\
\hline $6-7$ & Second Compression & Polytrophic & $T_{7}=T_{6} \varepsilon^{k_{p 3}-1}$ \\
\hline $7-8$ & Exhaust Heat Recovery & Isochoric & $n_{8}>n_{7}$ \\
\hline $8-9$ & Second Expansion & Polytrophic & $T_{9}=\frac{T_{8}}{\varepsilon^{k_{p 4}-1}}$ \\
\hline $9-10$ & $\begin{array}{l}\text { Second Pressure } \\
\text { Blowdown }\end{array}$ & Isochoric & $P_{10}=P_{0}$ \\
\hline $10-0$ & Exhaust & Isobaric & $T_{10}=T_{\text {res }}$ \\
\hline
\end{tabular}

Taking into account the kinematic properties of the novel mechanism, the $P V$ diagram for the idealized cycle is as shown in Figure 9. 


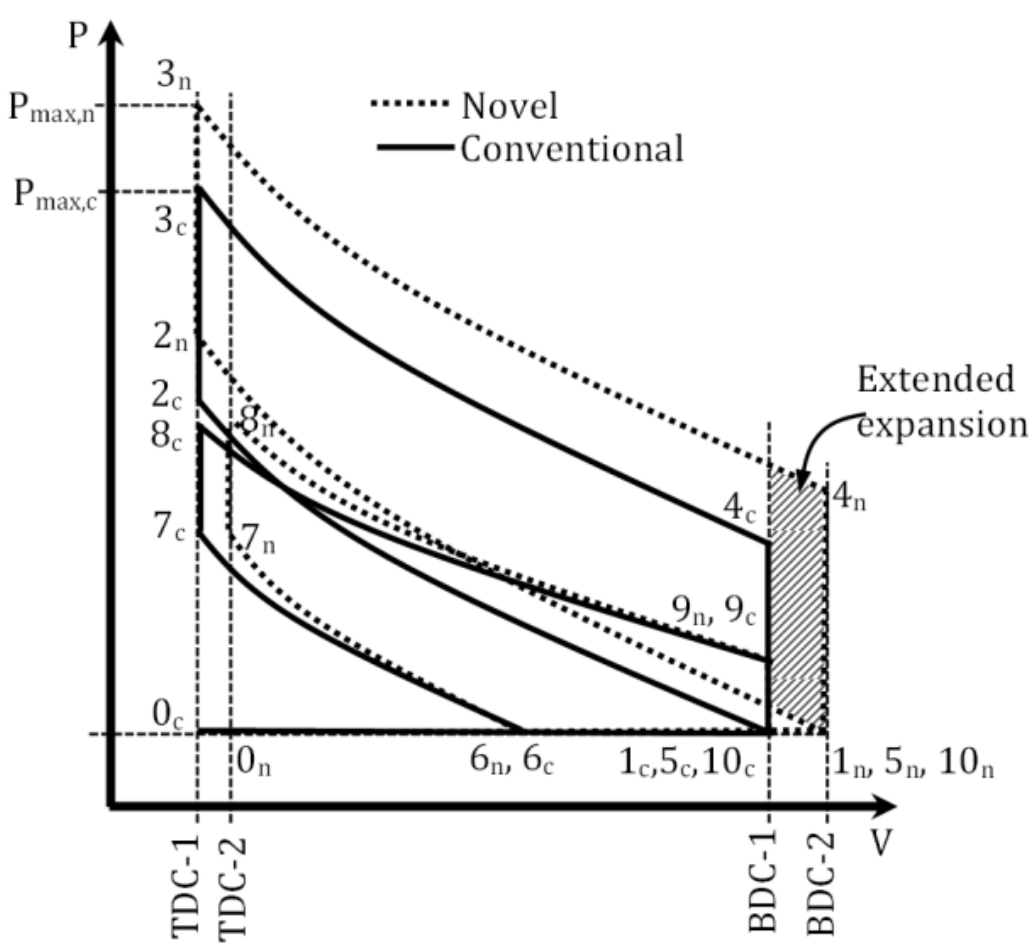

Figure 9. PV diagrams of idealized novel and conventional six-stroke engine cycles [5, 28]

TDC- 1 and BDC- 1 are dead centers for the conventional motor mechanism. The TDC- 2 and BDC-2 are additional new dead centers created by the novel engine mechanics. Thanks to these new dead centers, different compression and expansion ratios are obtained. The range of $0-1$ is the suction (or called intake) process, and the novel engine mechanism is about $7 \%$ more mixture than the conventional engine mechanism. Compression ratios of novel and conventional engine mechanisms are 9.7 and 8.6 respectively. In the expansion process occurring range of 3-4, the compression ratios of novel and conventional engine mechanisms are still the same. This is a different situation than the known Atkinson or Miller cycle, where the rate of expansion of the Atkinson or Miller cycles is greater than the compression ratio. When the compression ratios of both mechanisms are equalized, less energy is applied to the cycle as the suction process of the novel engine mechanism is shortened. Therefore, the novel engine mechanism is applied to the engine characteristics by keeping the amount of energy put in constant and the compression ratio of the novel engine mechanism is considered to be the advantage of this mechanism. In other words, instead of keeping the compression ratios of the two engine cycles equal in this study, the amount of fresh fuel-air mixture in a cycle is kept equal.

The following assumptions have been made for the cycle analysis [8, 27, 28]:

- All processes are in "steady state".

- $\left(\mathrm{C}_{8} \mathrm{H}_{18}\right)$ is used as the fuel.

- All gases that form the gas mixture are ideal.

- Specific heats do not change according to temperature.

- The exhaust gas from the previous cycle is the volume of the combustion chamber, and the exhaust gases consist only of $\mathrm{H}_{2} \mathrm{O}_{\text {vapor, }} \mathrm{CO}_{2}$ and $\mathrm{N}_{2}$.

- During the intake and compression processes, there is a homogenous gas mixture in the cylinder which is composed of fuel vapor, air and residual gases and is not reactive.

- At the end of combustion, adiabatic flame temperature is reached.

- Water injection and exhaust heat recovery are performed

- All state changes in the system occur as a steady state.

The processes in the cycle are as shown in Table 1.

For a process in the range $A-B$, the energy equation can be expressed as follows for isoboric, isochoric processes [30].

$$
\left(U_{B}-U_{A}\right)_{\text {isobaric }}=-p_{\text {constant }}\left(V_{B}-V_{A}\right)+\left(n_{B}-n_{A}\right) h_{\text {gas }}
$$




$$
\begin{aligned}
& \left(U_{B}-U_{A}\right)_{\text {isochoric }}=\left(n_{B}-n_{A}\right) h_{\text {gas }} \\
& W_{A B}=p\left(V_{B}-V_{A}\right)
\end{aligned}
$$

The highest combustion temperature can be reached after adiabatic combustion. The adiabatic combustion that occurs in the interval of 2-3 can be expressed as follows [30].

$$
\sum n_{3}\left(\bar{h}_{f}^{o}+\bar{h}-\bar{h}^{o}-R_{u} T\right)_{3}=\sum n_{2}\left(\bar{h}_{f}^{o}+\bar{h}-\bar{h}^{o}-R_{u} T\right)_{2}
$$

The combustion equation used for the combustion process is as follows:

$$
\begin{gathered}
\underbrace{\mathrm{C}_{8} \mathrm{H}_{18}+12,5\left(\mathrm{O}_{2}+3,76 \mathrm{~N}_{2}\right)}_{\text {fresh mixture }}+\underbrace{\frac{1}{r_{v}-1}\left[(\text { res })_{0}\right]}_{\text {residual gas }} \\
\rightarrow\left(8 \mathrm{CO}_{2}+9 \mathrm{H}_{2} \mathrm{O}+47 \mathrm{~N}_{2}\right)+\frac{1}{r_{v}-1}\left[(\text { res })_{0}\right]
\end{gathered}
$$

Here, $(r e s)_{0}$ and $r_{v}$ express the compression ratio of the exhaust after-burning exhaust gas and the partial exhaust process, respectively. The work in the polytropic processes that take place in the A$\mathrm{B}$ range is expressed as follows [30].

$$
\begin{aligned}
& W=C \frac{v_{B}^{-k_{p}+1}-v_{A}^{-k_{p}+1}}{-k_{p}+1}=\frac{n_{m i x} R_{u}\left(T_{b}-T_{a}\right)}{1-k_{p}} \\
& k_{p}=\left|\log _{\left(\frac{V_{B}}{V_{A}}\right)}\left(\frac{p_{B}}{p_{A}}\right)\right|
\end{aligned}
$$

The change in cylinder pressure obtained by the thermodynamic calculations made according to the reference engine specifications in Table 2 is as follows.

Table 2. Specifications of the reference engine [31]

\begin{tabular}{ll}
\hline Parameter & Value \\
\hline Number of Cylinders & 1 \\
Net power (@3600 rpm) & $6.3 \mathrm{~kW}$ \\
Net moment(@2500 rpm) & $19.1 \mathrm{Nm}$ \\
Displacement & $265 \mathrm{cc}$ \\
Strok $(2 r)$ & $60 \mathrm{~mm}$ \\
Conrod $(l)$ & $150 \mathrm{~mm}$ \\
Diameter of cylinder $\left(D_{c y l}\right)$ & $75 \mathrm{~mm}$ \\
Static compression ratio $(\varepsilon)$ & $8.6: 1$ \\
\hline
\end{tabular}

According to the reference engine specifications (Table 2) and the accepted conditions (Table 1), the in-cylinder pressure (a) and temperature (b) change in one cycle is as shown in Figure 10. 

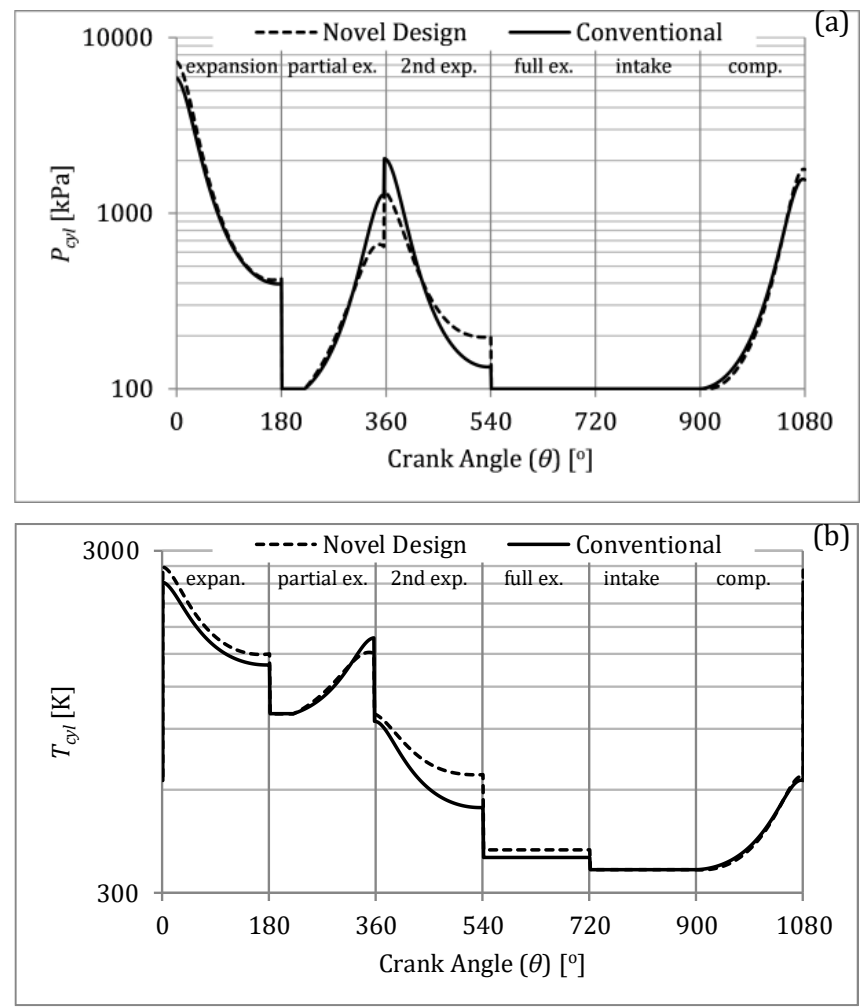

Figure 10. In-cylinder pressure (a) and temperature (b) change in one cycle

In the above assumptions, this engine cycle was assumed to be steady-state. Steady-state cycles occur in infinite time, and the engine power which is derivative of the time cannot be mentioned. However, in this study it is assumed that the engine operates at $3000 \mathrm{rpm}$ in order to give an idea for engine performance. The moment variation can be calculated with Equation 19. The torque obtained from the engine can be calculated as follows [27].

$$
\tau_{i}=\sum_{\theta=0}^{1080} \frac{\tau_{(\theta)}}{1080}
$$
$[5,28]$.

The relationship between power $\left(P_{i}(\mathrm{~kW})\right)$ and moment $\left(\tau_{i}(\mathrm{Nm})\right)$ can be expressed as follows

$$
P_{i}=\frac{\tau_{i} \cdot N \cdot 2 \pi}{60.1000}=\frac{W_{n e t} \cdot N}{60.3}
$$

The Eq. 28 can be reformulated to calculate the net work $\left(W_{\text {net }}(\mathrm{kJ})\right)$.

$$
W_{\text {net }}=\frac{6 \pi \tau_{i}}{1000}
$$

The calculated $W_{\text {net }}$ consists of the sum of two different work areas as shown in Figure 9. Indicated mean effective pressure (imep $(\mathrm{kPa})$ ) is an average value for the entire cycle, so it can be expressed as follows for six-stroke engines.

$$
\text { imep }=\frac{W_{n e t}}{2 V_{h}}
$$



follows.

Thermal efficiency $\left(\eta_{t h}\right)$ and specific fuel $(\mathrm{sfc}(\mathrm{g} / \mathrm{kWh}))$ consumption can be expressed as

$$
\begin{aligned}
\eta_{t h} & =\frac{W_{\text {net }}}{Q_{\text {in }}}=\frac{W_{\text {net }}}{n_{\text {mix }} Q_{\text {lhv }}} \\
\text { sfc } & =\frac{3600}{Q_{\text {lhv }} \eta_{t h}}
\end{aligned}
$$

$Q_{l h v}$ is the lower heat value of the fuel and it can be considered as $4962 \mathrm{~kJ} / \mathrm{mol}$ for $C_{8} H_{18}$.

\section{Results and Discussion}

By considering the properties of a four-stroke engine, theoretically, six-time conventional and overexpanded engines are assumed and kinetic, dynamic and thermodynamic calculations are made. In the calculations, the amount of fresh fill is equal for both six-stroke engines.

\subsection{Effects of design parameters on kinematic properties}

The novel design mechanism can be expressed as the maximum stroke " $r+d$ ". Accordingly, the effect of the change of $r / d$ on the piston motion is as shown in Figure 11, provided that the maximum stroke $(r+d)$ is constant. The large value of $d$ increases the irregularity of the piston movement. For this reason, the value of $d$ should be chosen as small as possible.

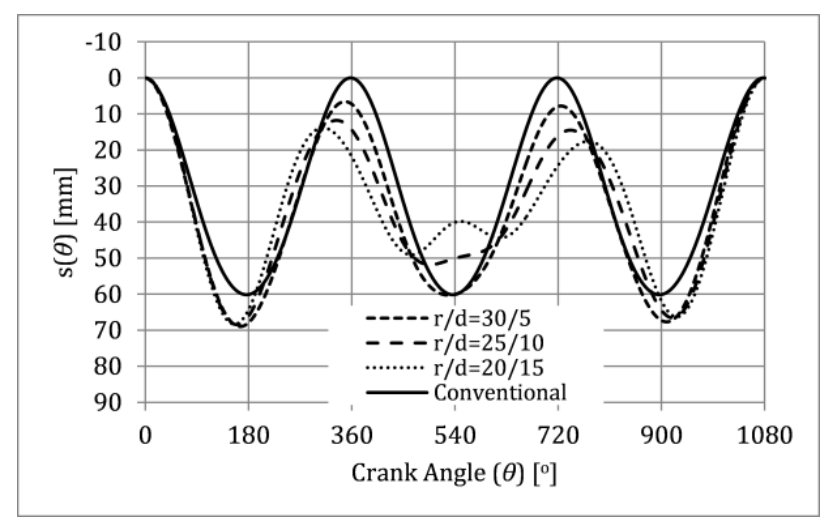

Figure 11. Change of piston movement according to $r / d$

Initially, since the axis is at the $y$-axis, the $y$-angle $\pi / 2 \operatorname{rad}$ with the $x$-axis of this axis is. The effect of the change in $\gamma$ angle on the piston motion is shown in Figure 12. As can be seen, the change in $\gamma$ angle causes an irregular piston motion.

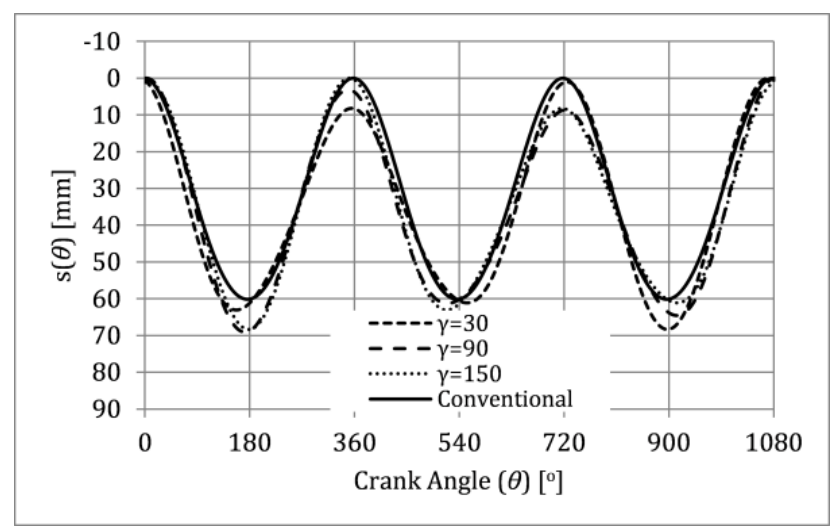

Figure 12. Change of piston movement according to $\gamma$ angle. 
The decision of design parameters that directly affect kinematic properties is crucial to engine performance. For a known $r+d$ value, the $r / d$ ratio should be as large as possible and the $\gamma$ angle should be $\pi / 2 \mathrm{rad}$ so that the desired piston motion can be achieved.

\subsection{Kinematic comparison of conventional mechanism with novel mechanism}

In the novel design, the parameter that changes the over-expanded effect is $d$. For kinematic comparison, technical data of a reference engine is used in Table 2. For the novel six stroke engine, $d$ is assumed to be $5 \mathrm{~mm}$.

For conventional and novel six-stroke engines, change of piston displacement according to crank angle Figure 13. Piston displacement in the expansion process of the novel model is more than that of the conventional model. However, the exhaust process is shorter than the conventional model, and at the end of the exhaust process, more waste exhaust gas remains in the cylinder in the novel model. However, a waste gas mixture (humidified exhaust gas) with a high water content is obtained thanks to the water injection and the exhaust heat recovery process which takes place before the exhaust stroke. Although this issue is ignored for now, the fact that the humidified exhaust gas is combined with the fresh intake mixture may be beneficial in terms of emissions and/or performance.

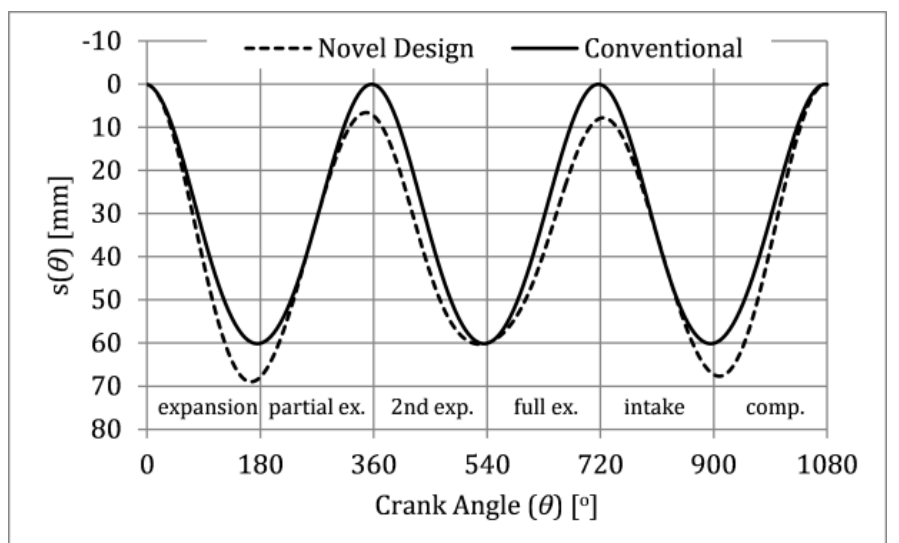

Figure 13. Change of piston displacement due to crank angle

Another parameter that is used to compare the two mechanisms and affects the formation of engine moment is the $\beta$ angle of the conrod with the piston vertical axis. Since the beta angle affects the friction between the piston cylinder (see Figure 7), in an engine design, $\beta$ angle is desired to be as small as possible [32-33]. While the $\beta$ angle is uniformly changed (such as sine wave) in the conventional engine mechanism, a different $\beta$ angle change curve is formed for each revolution in the novel engine mechanism. The change of $\beta$ angle due to crank angle is shown in Figure 14. Compared with the conventional model, the $\beta$ angle is wide in the 2 nd expansion and full exhaust processes, while the other processes are small. From the $\beta$ angle, it can be said that the novel model is advantageous compared to the conventional model.

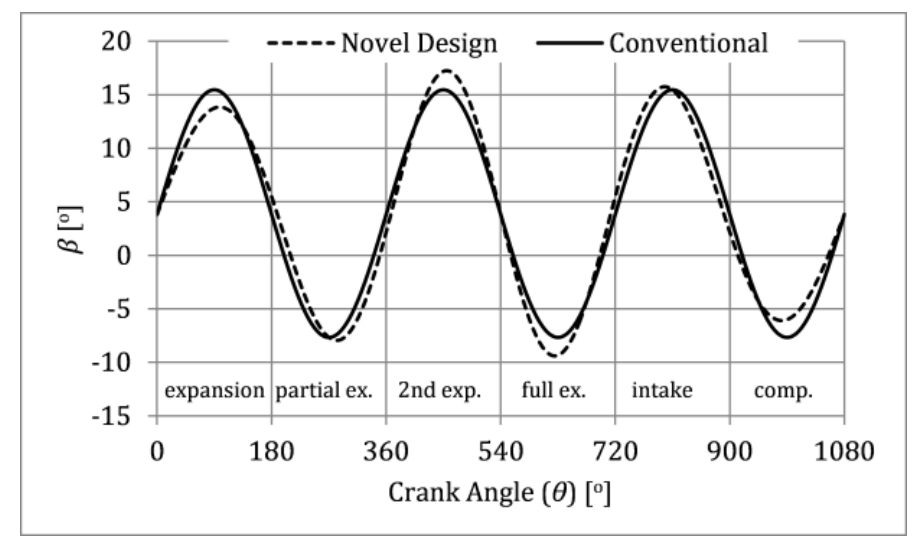

Figure14. Change of $\beta$ angle due to crank angle 
Since the piston movement characteristics are different in the two models, the instantaneous compression ratio ( $\left.\varepsilon_{\text {instant }}\right)$ can be different. While the bottom dead center (BDC) and top dead center (TDC) do not change in the conventional engine mechanism, BDC and TDC in the novel mechanism differ for each process in the cycle. For example, in the expansion process, $\varepsilon_{\text {instant }}$ ranges from 2.1 to 9.7 in the absorption process, while varying in the range of 1-9.7. When the expansion process changes in the range of 1 to 8.6 in the conventional engine, it is seen that the expansion process with the novel mechanism is extended by approximately $14 \%$. For both engines, while the $\varepsilon_{\text {instant }}$ change in the suction process is equal, the novel mechanism has a larger volume at the begining of the suction process. There is a similar situation for other processes. Compression ratio changes depending on crank angle is shown in Figure 15.

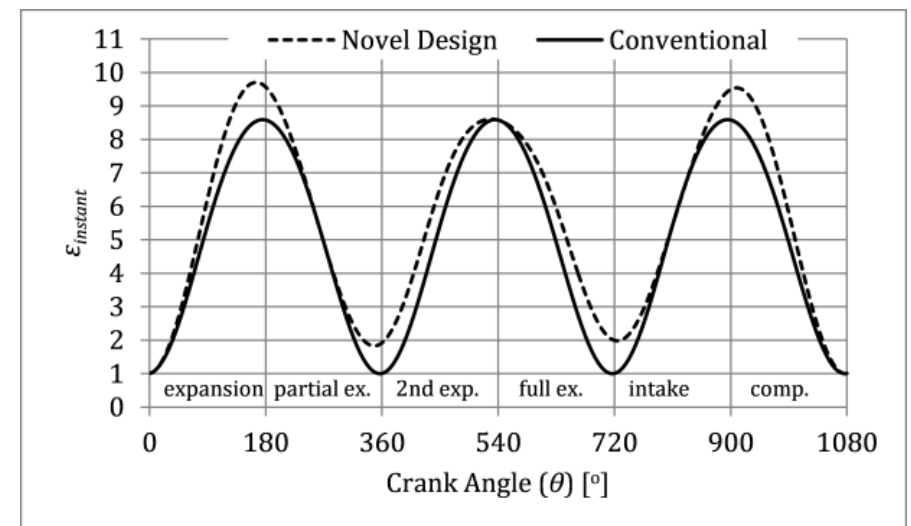

Figure 15. Change of compression ratio $(\varepsilon)$ due to crank angle

Figure 16 and Figure 17 show the changes in piston velocity and piston acceleration due to crank angle, respectively. In the novel model, the piston velocity change during the expansion and compression process is high in the conventional model and low in the other processes.

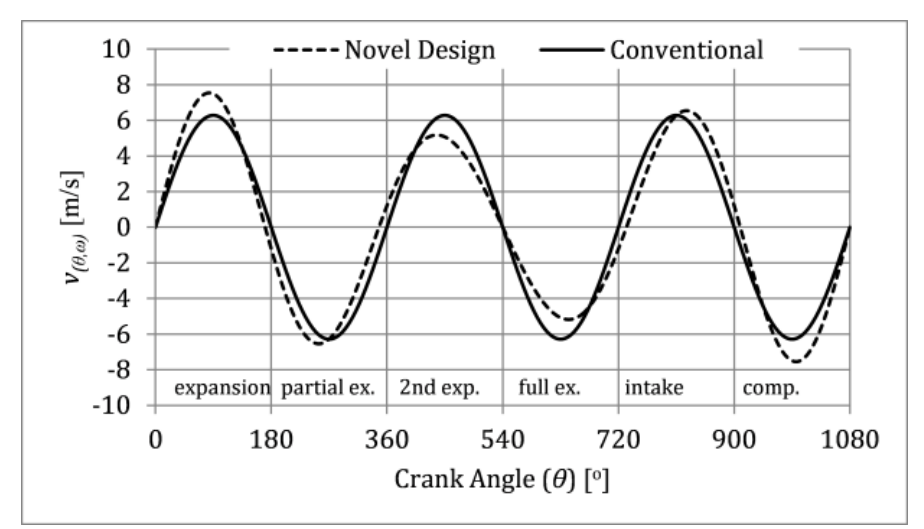

Figure 16. Change of piston velocity (v) due to crank angle

When the piston acceleration is examined, the instantaneous piston acceleration change in the novel model is somewhat complicated (irregular) compared to the conventional system. 


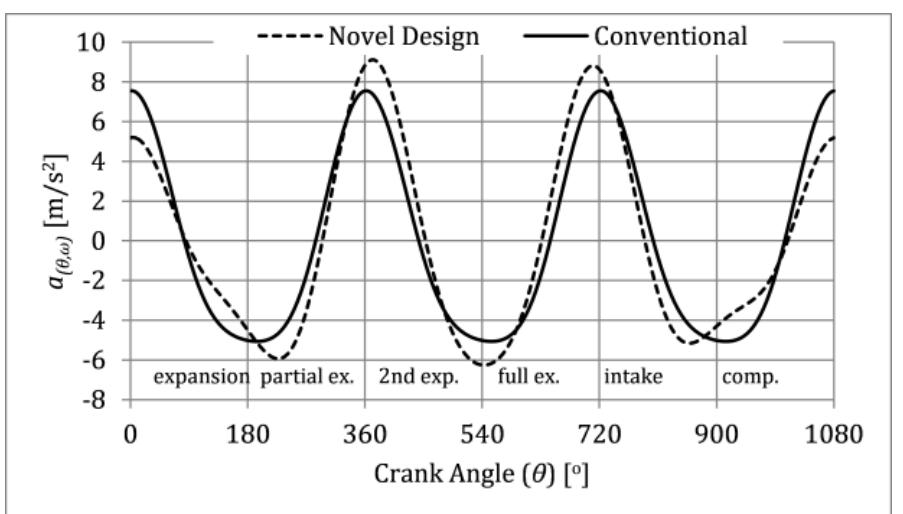

Figure 17. Change of piston acceleration (a) due to crank angle

By changing the engine characteristic values, it is possible to set the irregularly structured parameters to the desired level. When Figure 13 is analyzed, the replacement of the novel model by piston differs from the conventional model. The trend in Figure 16 is similar to Figure 13. However, since the acceleration change curve in Figure17 was examined, the acceleration peak point in the bottom dead center (BDC) at the end of the expansion process was moved to the after bottom dead center (aBDC), and the acceleration peak point at the end of the suction process in the BDC was moved to before BDC (bBDC). This is an effect of a completely novel mechanism.

\subsection{Effects of design parameters on dynamic properties}

By using Eq. 19, one cycle of moment change can be obtained (Figure 18). Compression ratio of novel design is more than conventional mechanism. For this reason, the instantaneous maximum moment generated by the combustion effect is higher in the novel design.

When the average moment values are examined, the average moment value of novel design is determined to be about $10 \%$ higher than the conventional mechanism. Along with the moment change, the load acting on the crankshaft is also affected. For this reason, it is necessary to examine the load acting on the crankshaft with this moment change. The change in the force acting on the crank bearing in one cycle is as follows (Figure 19).

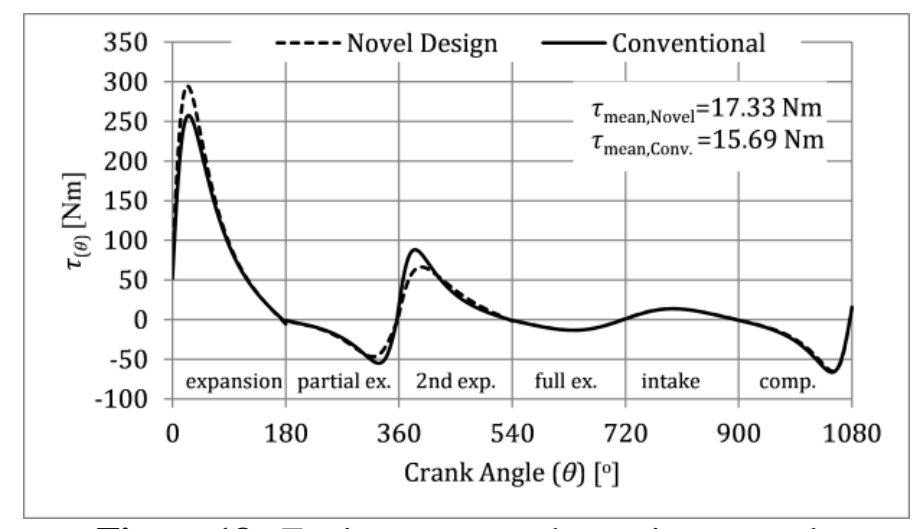

Figure 18. Engine moment change in one cycle 


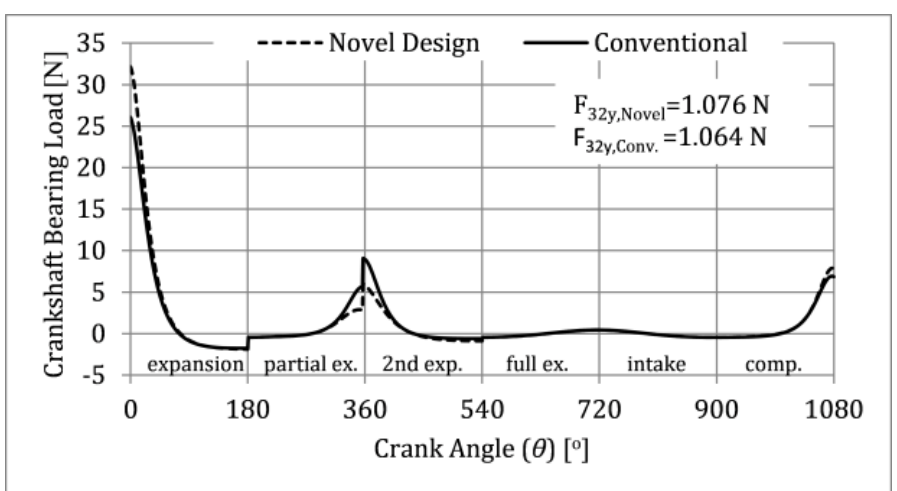

Figure 19. Crankshaft bearing load change in one cycle

When Figure 18 and Figure 19 are examined together, the novel design results in an increase of about $10 \%$ in engine moment, while a force on the crankshaft bearing has only increased by $1 \%$. Despite the increase in engine torque, the increase in the load in the crankshaft bearing is a positive and significant improvement in the mechanical performance of the engine.

\subsection{Engine performance results}

The purpose of thermodynamic analysis in this paper is not to determine engine performance but to determine the effects of two different (cenventional and novel) mechanisms on engine performance. However, in order to determine the $F_{g}$ used in the dynamic analysis, a thermodynamic model was created. Therefore, according to the thermodynamic model presented as simple as possible, indicated power $\left(P_{i}\right)$, net work $\left(W_{\text {net }}\right)$, indicated mean effective pressure (imep), Thermal efficiency $\left(\eta_{t h}\right)$ and specific fuel consumption (sfc) values from the engine performance parameters are presented in Table 3.

Table 3. Engine performance results (for $N=3000 \mathrm{rpm}$ )

\begin{tabular}{lll}
\hline Performance parameters & Conventional model & Novel model \\
\hline Indicated power $\left(P_{i}\right)$ & $4.93 \mathrm{~kW}$ & $5.44 \mathrm{~kW}$ \\
Net work $\left(W_{\text {net }}\right)$ & $296 \mathrm{~J} / \mathrm{cycle}$ & $326 \mathrm{~J} / \mathrm{cycle}$ \\
Indicated mean effective pressure $(i m e p)$ & $558.02 \mathrm{kPa}$ & $616.34 \mathrm{kPa}$ \\
Thermal efficiency $\left(\eta_{\text {th }}\right)$ & $39.3 \%$ & $43.3 \%$ \\
Specific fuel consumption $(\mathrm{sfc})$ & $206 \mathrm{~g} / \mathrm{kWh}$ & $187 \mathrm{~g} / \mathrm{kWh}$ \\
\hline
\end{tabular}

Table 3 shows that the novel engine mechanism improves engine performance. In order to make a comparison, it was accepted that fuel consumption were equivalent in both models.

\section{Conclusion}

The novel and conventional six-stroke engine mechanisms have been studied kinematically and dynamically. Kinematic and dynamic equations were obtained as a result of the study. Using the obtained equations, the effects of kinematic and dynamic properties of design parameters and optimum design parameters were determined. In order to dynamically to examine the effects of the novel designed mechanism, an idealized thermodynamic analysis was carried out and both models were compared. According to the results obtained, it was found that the torque value obtained in the novel designed engine mechanism in the idealized thermodynamic conditions is higher than the conventional engine, but there is no significant change in the load acting on the crankshaft bearing. As a result, the novel designed engine mechanism seems to be advantageous compared to the conventional engine mechanism. Nevertheless, although the novel designed engine mechanism is a very simple design, the desired end result cannot be guaranteed in practical applications. In fact, problems that have not been predicted until now may arise during practical applications. Until now, there has not been much practical or theoretical work on six-stroke engines. With this study, the disadvantages of six-stroke engines are thought to be advantageous with such mechanisms. Although six-stroke engines appear to be advantageous over four- 
stroke engines in terms of specific fuel consumption, the performance of six-stroke engines (especially power and torque values) must approach the performance of four-stroke engines as much as possible in order to increase the performance of the six-stroke engines. According to the engine performance results, the novel mechanism shows an improvement of approximately $10 \%$ in all performance parameters.

\section{References}

[1] Feidt M. 2017. Internal Combustion Engines Revisited. Finite Physical Dimensions Optimal Thermodynamics 1, Elsevier. 99-124. DOI:10.1016/B978-1-78548-232-8.50004-2.

[2] Reitz R.D., Duraisamy G. 2015. Review of high efficiency and clean reactivity controlled compression ignition (RCCI) combustion in internal combustion engines. Progress in Energy and Combustion Science, 48: 45-51.

[3] Ganesan V. 2018. Application of CFD for Analysis and Design of IC Engines. In Advances in Internal Combustion Engine Research,251-306, Springer, Singapore, DOI: 10.1007/978-981-107575-9_13

[4] Hentschel L., Michels K., Garbe T., Hönig M. 2018. E-fuels-a central module for future engine design?. In Internationaler Motorenkongress 2018, 487-489. Springer Vieweg, Wiesbaden.

[5] Arabaci E. 2018. A Novel Extended Expansion Engine Mechanism. International Journal of Automotive Science and Technology, 2 (2): 16-23.

[6] Zhao J. 2017. Research and application of over-expansion cycle (Atkinson and Miller) engines A review. Applied Energy, 185: 310-319.

[7] Arabaci E., İçingür Y. 2016. Thermodynamic investigation of experimental performance parameters of a water injection with exhaust heat recovery six-stroke engine, Journal of the Energy Institute, 89: 569-577.

[8] Conklin J.C., Szybist J.P. 2010. A highly efficient six-stroke internal combustion engine cycle with water injection for in-cylinder exhaust heat recovery, Energy, 35: 1658-1664.

[9] Arabaci E., İçingür Y., Solmaz H., Uyumaz A., Yılmaz E. 2015. Experimental investigation of the effects of direct water injection parameters on engine performance in a six-stroke engine, Energy conversion and Management, 98: 89-97.

[10] Szybist J.P., Conklin J.C. 2013. U.S. Patent No. US008291872B2. Washington, DC: U.S. Patent and Trademark Office.

[11] Postrzednik S. 2014. Effects of the water injection into the hot charge at isochoric conditions, Energy, 71: 7-20.

[12]Paul G., Das P.K., Manna I. 2015. Droplet oscillation and pattern formation during Leidenfrost phenomenon. Experimental Thermal and Fluid Science 60: 346-353.

[13] Kelem H., Kelem E. 2010. U.S. Patent No. 7,726,268. Washington, DC: U.S. Patent and Trademark Office.

[14] Khalife E., Tabatabaei M., Demirbaş A., Aghbashlo M. 2017. Impacts of additives on performance and emission characteristics of diesel engines during steady state operation. Progress in Energy and Combustion Science, 59: 32-78.

[15] Liu, F., Sun, B., Zhu, H., Hu, T., Du, W. 2014. Development of performance and combustion system of Atkinson cycle internal combustion engine. Science China Technological Sciences, 57: 471-479.

[16] Naber J.D., Johnson, J.E. 2014. Internal combustion engine cycles and concepts. Alternative Fuels and Advanced Vehicle Technologies for Improved Environmental Performance, Woodhead Publishing. 197-224. DOI: 10.1533/9780857097422.2.197.

[17] Murtaza G., Bhatti A.I., Arshad A. 2017. Nonlinear Robust Control of Atkinson Cycle Engine. IFAC-PapersOnLine, 50: 3685-3690.

[18] Siczek K.J. 2016. Valve train thermodynamic effects. Tribological Processes in the Valve Train Systems with Lightweight Valves, Butterworth-Heinemann, 39-58. DOI: 10.1016/B978-0-08100956-7.00015-1

[19] Gleich A. 2016. German Patent No: DE201510002385, Deutschland, German Patent and Trademark Office.

[20] CTL engine Mechanism, CTL-Engineering, 2018. http://www.ctl-engineering.com, (accessed on 2018-02-01). 
[21] Catalano G. 2018. Compact And Modular Atkinson Cycle Engine, from https://contest.techbriefs.com/2016/entries/automotive-transportation/7029, (accessed on 2018-0320).

[22] Lugo Engine, 2018. http://lugodevelopmentsinc.com, (accessed on 2018-03-10).

[23] Guimaraes, B., UMotor - Over-Expanded 2018. https://contest.techbriefs.com/2016/entries/sustainable-technologies/7088, (accessed on 2018-01$10)$.

[24] Waissi G.R. 1995. Internal combustion (IC) engine with minimum number of moving parts. In SAE Technical Papers DOI: 10.4271/950090

[25] Read T., 2009. U.S. Patent No. US8894530B1. Washington, DC: U.S. Patent and Trademark Office.

[26] Wiseman R., 2001. U.S. Patent No. US6510831B2. Washington, DC: U.S. Patent and Trademark Office.

[27] Caton J.A. 2015. An introduction to thermodynamic cycle simulations for internal combustion engines, John Wiley \& Sons.

[28] İçingür Y., Arabaci E. 2013. Altı Zamanlı Buji Ateşlemeli Bir Motorun Performans ve İdealleştirilmiş Hava-Yakıt Çevrimi Analizi. Politeknik Dergisi, 16 (1). DOI: 10.2339/2012.16.1, 37-44.

[29] Kolchin A. 1984. Design of Automotive Engines, Mir Publishers, Moscow, 24-82.

[30] Çengel Y.A., Boles M.A. 2014. Thermodynamics: An engineering approach. Boston: McGrawHill Education.

[31] Honda Motor Co., Honda GX 240, GX270, GX340, GX390 common service manual-part-c (2010). Honda Motor Co. Service Publications Office, Belgium, 1-2.

[32] Hoag K., Dondlinger B. 2015. Vehicular engine design. Springer.

[33] İpci D., Karabulut H. 2016. Thermodynamic and dynamic modeling of a single cylinder four stroke diesel engine. Applied Mathematical Modelling, 40 (5-6): 3925-3937, 